\title{
Student perceptions of a cybersecurity service-learning project
}

\author{
Kembley Lingelbach, Middle Georgia State University, kembley.lingelbach@mga.edu
}

\begin{abstract}
Cybersecurity skills and experience are needed to fill cybersecurity positions. Students can gain valuable experience through service-learning projects with professionals in the field to bridge the cybersecurity skills gap and to enter the workforce prepared. This research evaluated the benefits and engagement factors of a real-world penetration test through the perceptions of four IT students in a southeastern US university. By understanding the lived experiences of the participants, we determined skills gained and how to encourage other students to participate in future projects such as this. This research finds six overall themes to answer the questions of what are the benefits of the service-learning project and how to engage students in future service-learning projects? This focus group research resulted in six major themes: Students' perceptions of the quality of the service-learning project, improved knowledge and understanding, team collaboration; new skills and abilities, and experience shaped future goals, plans, or career interests and encouragement to peers. The research also determined strategies to engage college students to participate in service-learning projects. This information will help universities collaborate and develop appropriate service-learning projects with local industry, provide a meaningful experience for students and provide a service to the community.
\end{abstract}

Keywords: experiential learning, service-learning, penetration testing, cybersecurity

\section{Introduction}

The global shortage of cybersecurity professionals reached 4.07 million in 2019, with the U.S. gap almost 500,000 (ISC2, 2020). In September of 2020, Forbes reported that the talent shortage has increased more than anticipated and "while cybercrime is increasing exponentially, the supply for qualified security professionals is insufficient" (Sayegh, 2020). ISC(2) states, the gap is "the difference between the number of skilled professionals that organizations need to protect their critical assets and the actual capacity available to take on this work. It is not an estimate of open positions available to applicants" (p.17). Organizations are faced with challenges recruiting skilled cybersecurity professionals which leave them vulnerable to malicious cyber threats. As the gap increases, the nation is not protected from ransomware and "there is an urgency to defend against threats of today and secure against risks of tomorrow" (CISA, 2021). The Center for Strategic and International Studies (CSIS) surveyed eight countries and found that 82 percent of employees reported a shortage of cybersecurity skills and 71 percent believed that the shortage caused damage to their organizations (Crumpler \& Lewis, 2019). This research addresses the skills gap in the cybersecurity industry by promoting service-learning penetration testing projects.

\section{Experiential learning \& service-learning projects}

This research is viewed through the lens of the Experiential Learning Theory (ELT) and explains how a penetration testing project reinforces classroom knowledge and skills (Kolb \& Kolb, 2005). Experiential Learning Theory (ELT) is defined as "the process whereby knowledge is created through the transformation 


\section{Issues in Information Systems}

Volume 22, Issue 3, pp. 307-319, 2021

of experience" and is a continuous process (Kolb, 1984, p. 38). Experiential learning and service-learning projects provide many opportunities and benefits to higher education institutions, students and community. Experiential learning is learning from actual experience whereby the knowledge learned from the classroom is transformed in to a deeper understanding (Chan, 2012). Service-learning projects, as a subset of experiential learning, provides a mean by which students can gain real-world experience in collaborative environments with professionals in the field (Furco, 1996). Efficacy of utilizing service-learning projects and experiential learning has been shown to increase certain skills that include soft skills and technical skills required for entering the cybersecurity workforce (Pinnell \& Chuck, 2004). Learning occurs when individuals actively participate and engage in an activity (Haque, 2017). ELT explains how experience in performing activities enables learning and shapes an individuals' behavior and decisions. Students have limited options for internships, and cybersecurity entry level job qualifications list minimum requirements for experience, education and certifications for entering the workforce (Chen, 2018). However, classroom knowledge, cyber competitions and challenges can give students valuable knowledge, and hands-on practice, ELT and service-learning experience enhances the students' capabilities by augmenting classroom knowledge (Chan, 2012). IT Students have indicated in they prefer hands-on learning along with traditional classroom learning (Floyd, Harrington \& Santiago, 2009). Other studies suggest that service-learning and active learning in capstone courses reinforces student knowledge and skills when collaborating with the community on real-world projects (Beasley \& Floyd, 2013; Girard, Yerby \& Floyd, 2016).

\section{Service-learning benefits}

Prior Literature on service-learning benefits encompass many factors to the student such as gains in organizational knowledge and understanding, new skills, enhanced classroom knowledge, team collaboration and impact on future goals. Kwenani \& Yu (2018) indicates that students' perception of organizational knowledge is enhanced through service-learning projects. Whereas, Barr (2021) purports through marketing service-learning projects that classroom knowledge is transformed by practical application as it "promotes the classroom experience as more relevant and understandable" (Barr, 2021, pg. 1). Kwenani and $\mathrm{Yu}$ (2018) also suggests that connecting with other students in groups and exchanging ideas are seen to be an important benefit of volunteering and was the second most articulated theme for students. In an engineering and pre-service interdisciplinary service program, more effective teamwork skills were seen over time for student teams (Pazos, et. al., 2020). They indicate there was 'a significant gain in teamwork effectiveness through participation in an interdisciplinary collaboration experience' (pg. 9). Kwenani and $\mathrm{Yu}(2018)$ proposes that students gain new ideas, skills and knowledge when engaging in community service-learning projects that include communication skills and social skills like empathy, teambuilding skills and time management skills. However, Barr (2021) indicates in a study of marketing students that a 'premium is placed on students' technological skills" (pg.1). Gaining confidence was also seen in student abilities while working in teams (Barr, 2021). Kwenani and $\mathrm{Yu}$ (2018) saw a change in perspective with regard to future goals and career interest. They stated that additional benefits included help in finding a job or being accepted to graduate school, improving English-language skills, increasing selfconfidence, and gaining added awareness regarding future career choices. Barr (2021) conveyed that projects that are challenging and rewarding can have an impact on intention to continue to volunteer working in the community and students have communicated the value of building their work portfolio in the job market. Benefits such as leadership skills, soft skills and practical training skills have been seen to be fostered through service-learning projects (Barnett, Jeandron \& Patton, 2009; Debnath \& Farkhod, 2009; Furnell, 2020; Elsafty, et al., 2020). The nature of service-learning activities have primarily been in community service as humanitarian relief efforts (Huff, Zoltowski \& Oakes (2016). However, they propose for the purpose of training students, long term projects can be extended to engineering and STEM fields. Overall, service-learning in general generates positive benefits to the engineering students that include personal development, tolerance for diversity, interpersonal development, community to college 


\section{Issues in Information Systems}

Volume 22, Issue 3, pp. 307-319, 2021

connections, self-efficacy with recruitment and retention as the motivating factors (Duffy, Barrington \& Heredia, 2009). Duffy, et al. (2009) also suggest the students are motivated to help others in their profession. There are many studies on service-learning in fields such as in the health and medical fields, pre-service teaching, business and engineering, however, research is scarce in the cybersecurity field. What we do not know is how service-learning in the cybersecurity field can be beneficial to this population.

\section{Cybersecurity skills}

The Center for Strategic and International Studies (CSIS) found that "IT professionals still considered technical skills like intrusion detection, secure software development and attack mitigation to be the most difficult to find skills among cybersecurity operators" (Crumpler \& Lewis, 2019, p. 2). Skills required for penetration testing and vulnerability assessments include both technical and soft skills (Debnath \& Farkhod, 2009). Furnell (2020) stated, "it is worth recognizing that cybersecurity covers a broad spectrum of skills, spanning both technical and non-technical elements"(pg.1). Debnath \& Farkhod (2009) suggest that organizations hiring penetration testers, the skills should include both technical and soft skills that include knowledge of application and network penetration testing tools and exploits, identification of vulnerabilities, report writing skills, ability to explain technical issues to a non-technical audience, customer relationship management skills, database knowledge, web applications, knowledge of more than one operating system, training skills, at least two years of experience in application and network testing and ethics and legal issues involved in testing (Debnath \& Farkhod, 2009, p. 3). Other competencies mentioned were specialized testing in SCADA, wireless, Bluetooth, VOIP, blackberry as well as network design, exploit development, security tool testing, and virtualization experience (p. 3). Skills and experience needed to fill cybersecurity positions are hard to obtain for college students, however, service-learning projects with professionals in the field can bridge the skills gap allowing collaboration with industries to gain realworld experience, knowledge and skills to enter the workforce prepared.

\section{Penetration testing}

Penetration testing and assessments identify security vulnerabilities and exploit them on behalf of the organization. Wai (2002) defines penetration testing as a means to identify vulnerabilities that exists in a system or network that has an existing security measures in place. A penetration testing team emulates malicious hackers and use the same tools, techniques and practices as well as the mindset of a hacker to perform a service to the organization. By emulating hacker techniques, the penetration test team can provide valuable information to the organization to be proactive in protecting their valuable data, assets and personal identifiable information (PII) from internal and external attacks. Wang \& Kou (2012) suggest there are three phases of penetration testing that include pre-attack phase, attack phase and post-attack phase. Graves (2010) proposes five phases as reconnaissance, scanning, maintaining access and covering tracks and added planning and reporting as a pre and post phase. The process used in the project studied for this research utilized the planning, reconnaissance, scanning, gaining access, maintaining access, and reporting phases. This research is designed to assess the benefits of experiential learning projects, in particular, servicelearning projects where experience with local organizations and professionals in the cybersecurity field can be shown to provide the needed skills for the workforce.

\section{Purpose}

This research is designed to understand the perception of the participants to gain a deeper understanding of their overall experiences. By understanding the lived experiences of the participants, we can determine the impact factors of service-learning on cybersecurity students and how to encourage other students to participate in future projects. The purpose of this qualitative focus group study is to determine the means 


\section{Issues in Information Systems}

Volume 22, Issue 3, pp. 307-319, 2021

of engaging future students to participate and learn what benefits the participants perceived. Specifically, the research will seek to answer the following questions: What are the benefits of the service-learning project and how to engage students in future service-learning projects?

\section{Methodology}

\section{Project background}

The university was approached in January 2020 by a local insurance company who were also members of the university technical advisory board to offer a project for IT students to conduct a penetration test and assessment of their network and IT assets. This project was to be a service to the organization to assist with audit compliance as well as a service to the students with actual hands-on experience. Prior to development and proceeding with the project, memorandum of agreements (MOAs) and non-disclosure agreements (NDAs) were developed and agreed upon by the university and the insurance company. This process was time extensive and required multiple reviews by both parties legal counsel. By November 2020, a special topics course in information technology was developed and scheduled for spring 2021. Announcements advertising the course and the opportunity to participate in a real-world penetration was sent via email to all IT program students in late Fall 2020 to generate enrollment. An option was given to the IT students to volunteer for the project or enroll for course credit. 16 students replied with interest, however, interested students, only four students participated in the penetration testing project. The IRB process began and was approved as there were no risk other than what occurs from day to day. Only one of the four students enrolled for course credit, while the other three students surveyed the course as observers. However, all four participated in the penetration testing project. The enrolled student was required to submit coursework that included the planning documents, weekly reports and presentation for credit that aligned with the following outcomes:

- Understand the fundamentals of penetration testing and reporting

- Plan a penetration testing schedule

- Design a penetration test plan

- Conduct a penetration test according to plan

- Develop a penetration testing report

- Present presentation results

During the semester, weekly online meetings were conducted with the faculty and students for team reflection and understanding of the requirements, plans, schedule, tools, and the scope or rules of engagement (ROE). The ROE was identified through collaboration with management of the insurance company. The student team also met virtually via Discord to share planning documents and develop their plan of action for the penetration test. This student-led project covered each learning outcome that included a schedule, a plan based on the scope provided by the company, selection of tools for each area in the scope, written analysis report and presenting pre-test presentation as well as a results presentation to the senior management of the company. The team conducted a penetration test utilizing tools they were familiar with and given the scope of the test, they were given a range of IP addresses to scan for vulnerabilities, they also assessed the wireless network, as well as limited physical security assessments. Social engineering, and exploitation was taken out of the scope to prevent any damage to the network or assets. The penetration test was scheduled from $4 \mathrm{pm}$ until $8 \mathrm{pm}$ in late April 2021 at the insurance company location. The first hour included a kick-off presentation with management. The total test lasted approximately three hours. The students were invited to participate in this research study as the penetration testing and assessment concluded by email. This research paper does not discuss the findings (vulnerabilities) of the penetration 


\section{Issues in Information Systems}

Volume 22, Issue 3, pp. 307-319, 2021

testing as it is sensitive information and per the non-disclosure agreements. Specifically, the study answers the following questions: What are the benefits of the service-learning project and how to engage students in future service-learning projects?

\section{Research design}

Qualitative research was chosen to gain a deeper understanding into the lived experiences of the participants. There is a gap in service-learning research with respect to teams and call for additional qualitative research. Focus group interviews were chosen to interview the participants as a team to gather in-depth and rich data, and is used for participatory and action research (Morgan, 1996; Morgan 2002). Onweugbuzie, et al. (2009) suggested using 'mini' focus groups for three or four participant when difficulties in recruiting participants exist. Prior to the focus group interviews a pre-survey was conducted to gain demographic data and short answers to open-ended questions to serve as a guide for the focus group interview.

\section{Sample}

Upon approval from the university's Institutional Review Board (IRB), a purposive sample of four (4) undergraduate students enrolled in the IT program at a public university in the southeastern United States was invited to take part in the study. Recruiting participants began during the spring semester 2021 at the conclusion of a penetration test service-learning project which was part of a special topics course in IT. The sample consisted of four students who participated in the special topics course penetration testing project.

\section{Instrumentation}

The instrument for this study was only used only as a guide and a pre-survey to a focus group interview. The survey consisted of 24 questions. Questions 1-6 were used to retrieve demographic information. Questions 7-24 were open-ended questions to guide or learn about in-depth perceptions of the participants' experience. The questions and focus group questions were designed by the researcher. The questions focused on the quality of the project and the benefits and engagement factors.

\section{Procedures}

All four participants confirmed and signed informed consent to be interviewed. After receipt of the informed consent forms, a focus group pre-survey was administered electronically using Survey Monkey®. The pre-survey was used to obtain demographic information and results from the 24 open-ended questions were used to guide the focus group interviews. The focus group was schedule online with Zoom and interviews were recorded and transcribed by the researcher to gain further in-depth data. An email containing a hyperlink to the pre-survey was sent electronically to the four participants student university email accounts with an invitation to the virtual focus group interview. The participants were guaranteed the anonymity in reporting and were assured that responses would not be shared. The raw data consisting of interview transcripts and survey data was imported into Quirkos for data processing and analysis. The demographic data was entered into a spreadsheet for descriptive analysis. 


\section{Results}

\section{Participants}

Demographic data was collected and is presented in Table 2. Four (4) students in the IT program participated. All participants were male and at senior level class standing. The ages ranged from 22 to 47 . All of the students were information technology majors with three in the cybersecurity concentration and one in the digital forensics concentration. Half of the respondents viewed the penetration test project as excellent and the other half viewed the project as good.

Table 2: Descriptive Statistics for

Penetration Testing Project Research

\begin{tabular}{|l|l|l|l|l|l|}
\hline Participant & Gender & Age & $\begin{array}{l}\text { Class } \\
\text { Ranking }\end{array}$ & $\begin{array}{l}\text { Program } \\
\text { Concentration }\end{array}$ & $\begin{array}{l}\text { Overall } \\
\text { Perception }\end{array}$ \\
\hline$\# 1$ & Male & 22 & Senior & Cybersecurity & Excellent \\
\hline$\# 2$ & Male & 29 & Senior & Cybersecurity & Good \\
\hline$\# 3$ & Male & 31 & Senior & $\begin{array}{l}\text { Digital } \\
\text { Forensics }\end{array}$ & Good \\
\hline$\# 4$ & Male & 47 & Senior & Cybersecurity & Excellent \\
\hline
\end{tabular}

\section{Data analysis}

The raw data consisted of focus group interviews and pre-focus group surveys. The interview data and the open-ended question survey data were transcribed by the researcher and imported into a qualitative data analysis tool, Quirkos. Quirkos was used for qualitative data analysis of each sentence in the interview transcripts to determine overall categories and themes to answer the research questions. Each sentence in the transcript was analyzed to discover codes, categories and general themes. The interview surveys were gathered through SurveyMonkey prior to the focus group interview to gain more in depth insights and the focus group interviews were recorded and approved by each participant for reliability. The coding process via Quirkos resulted in 104 codes, 24 categories and reduced to six themes. The 104 codes were the initial words or phrases that answered the questions on the quality of the project, project benefits and engagement factors the students perceived. After the second pass, the 104 codes were organized into categories of quality and engagement factors (which were also considered to be student benefits). For example: There were 32 statements regarding the quality of the project and 52 statements on benefits or engagement factors. After the induction and deduction, the most frequently stated codes formed the six overall themes. The results spanned across these six major themes: Student perceptions of the quality of the service-learning project, improved knowledge and understanding, team collaboration; new skills and abilities, and experience shaped future goals, plans or career interest, and encouragement to peers.

\section{Overall themes}

\section{Quality of the service-learning project}

Overall perceptions of the quality of the service-learning project was positive, however, there were suggestions on enhancements to the course project. The students were evenly split on ranking the quality as either 'good' or 'excellent'. The students believed the overall project experience allowed enrichment of knowledge, skills and abilities learned in the classroom as seen by a quote by one student, 'I believe this experience reinforced my classroom and lab learning and showed me what I will need to work on and improve for future projects" another student agreed they liked having a voice and having someone listen to 


\section{Issues in Information Systems}

Volume 22, Issue 3, pp. 307-319, 2021

what you had to say, as stated by another student, "When team lead presented [the results], the [company] executive was very interested and asking [asked] questions about how they can [secure their systems] and they listened to what we had to say". All four students agreed and were surprised with the results of the project as seen by this student's quote, "I was impressed for the amount of data we got in three hours!" which aligned with Barr (2021) that states working in teams that students will gain more confidence in their abilities over time. Only one student participated remotely [online] and felt that he did not gain the full experience, however, he was still a vital part of the team who made important suggestions during the test. He stated, "I would suggest a live feed of the penetration test for online students" and felt that "the best part [of the penetration test] was talking to [team members] and how they actually gained access to some sensitive files." This showed the collaboration of the team members and learning from each other supports recent research on service-learning team collaboration and effectiveness (Kwenani \& Yu, 2018; Pazos, et al., 2020). The students felt this project was an actual performance of what they have practiced in the classroom and in competitions. Some issues for the team is that the test could have been conducted throughout the semester to gain a more in depth experience "If we had more time, I think we may have gotten more in-depth test results, like, maybe a full semester" and another stated the course could have a practice lab for the start of the semester culminating with the real-world penetration testing project, "I think the course could be enhanced with yearly practice labs or class practice labs prior to the [real-world] pen test project".

\section{Improved knowledge and understanding}

Improved organizational knowledge and understanding as well as application of real-world projects have been shown to be enhanced in service learning projects (Beasley \& Floyd, 2013; Girard, Yerby \& Floyd, 2016; Kwenani \& Yu, 2018). In alignment with these prior studies, the students indicated the penetration testing project increased their understanding of the organization, "It deepened my understanding of business side of a penetration test" where another student confirmed Barr (2021) where practical application reinforces the classroom knowledge, "It gave us the opportunity to run through items on a live system that [we] would not have in practice labs; [The penetration testing project] reinforced things [processes] you need to do".

\section{Team collaboration}

Team collaboration and effectiveness are seen as a benefit and supported in the team collaboration theme were seen as a benefit in accordance with a recent study (Kwenani \& Yu, 2018; Pazos, et al., 2020). Kwenani and $\mathrm{Yu}$ (2019) stated that, "engaging with others, exchanging ideas, having a social experience, networking and getting to know more people and achieving a balance (having more activities out of the classroom/studying) were key factors of volunteering" (p. 8). Teamwork and collaboration was seen to be an important factor gained by participation in the project as seen by one student: "We had a great team and learned from each other!" and gained new skills from collaboration, "The best part was talking to [team members] and how they actually gained access to some sensitive files." The student participants collaborated virtually to develop their plan and roles, "We collaborated through email and Discord so that each person would have their individual parts [roles] ready" and the student team lead indicated that the team conducted and presented quality work, "Getting quality reports from the team members was excellent". However, the size of the team indicated by one student may have improved the results even more, "It [the penetration testing project] may have been better with more people - maybe a slightly bigger but with [students] that have worked together and know each other to help guide other students". The participants believed their close team cohesiveness contributed to the success of the project, as stated by one participant, "Since we were already in classes together and knew each other fairly well, we were a great team, we each had our own skills and learned from each other and that made a difference." 


\section{Issues in Information Systems}

Volume 22, Issue 3, pp. 307-319, 2021

\section{New skills and abilities}

The gaining or enhancement of skills and abilities through service-learning projects have been seen through prior research that include leadership skills, practical training, soft skills, technical skills, and enhanced confidence (Barnett, et al., 2009; Barr, 2021; Debnath \& Farkhod, 2009; Furnell, 2020; Elsafty, et al., 2020; Jeandron \& Patton, 2009; Kwenani \& Yu, 2018). The results of this theme aligned with this prior research. The participants indicated they learned new skills that included soft and technical skills. The technical knowledge gained were in the form of internal network, physical security walkthrough, and wireless vulnerability assessments. The project reinforced classroom knowledge where the tools utilized were used in the penetration test. The students used tools they were familiar with, however, they also learned of other tools and techniques from team collaboration as stated by one student, "Through formal deliberation in meetings and from the scope of what we were able to test. I think [the tools used were] mainly on the matter of what [penetration testing] tools we were comfortable with, but we did learn from each other". The soft skills that were learned were leadership, presentation and technical writing skills as stated by one student, "The project allowed me to improve my professional writing skills and presentation skills" and another stated, "I learned what a penetration test report looks like and how the general [technical process] procedures go". One student stated that his skills were reinforced by the experience, "It [the penetration testing project experience] reinforced of what I knew and what I need to learn, I feel sure [participation in] a second exercise I would be much better."

\section{Experience shaped future goals, plans or career interests}

This service-learning penetration testing project shaped future career goals and interest of the student participants. Prior research indicates service learning can shape future career goals, plans and interests in the career field (Barr, 2021; Kwenani \& Yu, 2018). Two of the students were focused on cybersecurity as a career after graduation and reinforced that interest with this project as seen by one student, "I already wanted to do penetration testing, so it helped me get a clearer picture of what [a real-world penetration test] consists of" and another student stated the penetration test project enhanced his interest, "It reinforced my interest in the network and wi-fi scanning portions of pen testing. We were really able to see the benefit of being able to get into the network". One student is focused more on research in the cybersecurity field, but provided insights into the benefit of a penetration testing. "My primary interests remain more research focused aspects of cybersecurity, [however] the experience has given me a much deeper understanding of the pen test process and how it may benefit a company's security posture". Two other students plan to use what they have learned from the project in their future career as stated by the first student, "I will use the report as a standard to adhere to when I will have to make reports in the future" and the second student indicated, "The aspects I've learned about professional writing, as well as giving presentations will certainly be utilized in my career" Another student suggested the experience showed him what he needs to focus on in the future, "I will learn more about how to get into a network, how to traverse it and how to stay there."

\section{Encouragement to peers}

In prior research, students that have participated in service-learning projects encourage fellow students to participate. They illustrate that projects that are challenging, rewarding and help the community have value to others and can add to their portfolios to enter the job market (Barr, 2021). All participants agreed they would encourage other students to participate to gain invaluable experience and to reinforce learning gained in the classroom as stated by one student, "I would encourage student to participate because it helps you understand the real world application of your learning" Overall, the students perceived the experience helped to bridge a gap between classroom learning and actual applied knowledge, and skills as stated by 


\section{Issues in Information Systems}

Volume 22, Issue 3, pp. 307-319, 2021

one student, "Because they [students] will gain invaluable experience. Our classes go a long way to inform us, but students still can develop a disconnect on what we have learned in classes and how it [knowledge and skills] may actually be applied." And another student suggested, "Experience such as this helps students bridge the gap between formal learning and real world application" and "It offers a degree of experience you can't get otherwise". However, another student indicated that prior knowledge is needed before attempting to participate on this type of project, "Classroom learning, labs and competitions are safe environments to practice in before actually attempting to participate on the project". The participants also believed the real-world experience gave them the needed experience that could be added to their resume as suggested by one student, "The biggest advantage is that this experience can be added to your resume" and another student stated, "I am not sure why students are not beating down the doors to participate. Perhaps shopping [advertising] it as a great resume enhancer" The student participants stated they would not discourage participation, but would encourage them to possess some knowledge and participate in cyber competitions prior to participating in a future project as seen by this student's quote, "I try to encourage my peers to participate in competitions to help convert their formal learning to hands-on skills. Competitions are very safe environment where real damage can rarely be done; however, projects such as this, have slightly more weight to them. I am certainly not attempting to state that an experience such as this should not be fun and informative, but I do believe students should properly understand that actions taken during an assessment [or penetration test] could have consequences for the company". One student stated, that targeting a students who are technically would engage interest, "If you are trying to build interest, push projects like this through other classes to engage interest, if you [students] are interested in the technical side, target those students." Other benefits that can engage students participate is that organizations can build their future workforce as seen by this student's statement, "This project can drive other organizations to participate and grow leaders for the future", where another student suggested adding course credit to participate, "Offer course credit [extra credit] in other courses to participate in the project". However, one student felt that some of the students that expressed interest, but did not participate did not understand the time commitment as stated by one student participate, "I feel the other students that did not participate did not know the time commitment involved so we need to elaborate on that next time".

\section{Discussion}

The findings were consistent according to qualitative approaches and include quotes from interviews and the pre-survey to support the findings. The thematic results of the project answered the two questions of what the benefits are to the student and how to engage student participation in the future. This project, not only enhanced classroom learning, but also allowed them to gain valuable experience needed to begin careers in the cybersecurity field. The soft skills included presentation and technical writing skills and customer relationship or networking; other engagement factors included: experience that can be added to a resume, service to self, service to community and team collaboration. The technical skills were learned from each other or reinforced from classroom knowledge and cyber competitions. They all felt they helped the organization find vulnerabilities and provided solutions and that the senior management listened to what they had to say. All participants stated they would willing participate in the project again and enjoyed the opportunity. Other factors that resulted from the analysis included mutual team respect, and a sense of accomplishment. The overall perception is the penetration testing project was a success, but did result in suggested improvements to future course projects. The students believed the project would be enhanced through increasing the course length to a full semester instead of a short session of eight weeks. Other suggestions included an addition of a mock penetration test prior to the actual project to practice. Lastly, faculty should provide streaming live video for online students to participate in the actual testing. 


\section{Issues in Information Systems}

Volume 22, Issue 3, pp. 307-319, 2021

\section{Limitations}

Limitations for this research include that generalizations may not apply due to the number of students involved, even though they are a subset of the population. The size of the population was small and participants were only male and senior-level class ranking. By engaging female students, minorities in other class rankings would generate a more a diversified experience and future cybersecurity workforce. Future research should also include utilizing other research methods which may increase the generalizability of the study as well as expanding the geographical location across the United States or other countries where the skills gap is even less. Additionally, future research recommendation is to investigate the community partnership perspectives on service learning projects and the value added benefits to the organization to determine how to best address the needs of the community. Comparisons can then be made to analyze the needed skills and abilities needed for future cybersecurity workforce. Additionally, future investigation may be to interview the students that declined participation in the project to determine what issues or barriers were preventing them from participation. Lastly, explorations should be conducted to determine the relationship of each engagement factor individually with any generic skills outcomes from the students.

\section{Conclusion}

There is a significant skills gap in the cybersecurity workforce and only expect to worsen in the next few years. This research addresses the benefits to students and engagement factors of recruiting student participants for real-world service-learning projects to alleviate the cybersecurity skills gap. The guiding research questions are: What are the benefits of the service-learning project and how to engage students in future service-learning projects? By understanding the students' perceptions of their experience, we learned that the benefits are the engagement factors to target other students to participate in projects in the future. This research is viewed through the lens of the Experiential Learning Theory (ELT) and explains how the penetration testing project reinforced classroom knowledge and skills to perform the tests (Kolb \& Kolbe, 2005). This research aligns well with experiential learning and service-learning studies purporting that classroom learning can be reinforced with hands-on projects (Beasley, 2003; Chan, 2012; Floyd, Harrington \& Santiago, 2009; Girard, Yerby \& Floyd, 2016). The experience gained through this project also supports studies that purport utilizing service-learning projects in advancing technical and soft skills, team collaboration, required for cybersecurity workforce (Debnath \& Farkhod, 2009; Furnell, 2020; Kwenani $\& \mathrm{Yu}, 2018$; Pazos, et al., 2020). The students gained experience they can add to their resumes and perceived the project to be challenging, rewarding and would be willing to participate again (Barr, 2021). This partnership is unique to the university and it is suggested that other partnerships with industry can be made to increase projects such as this in the future. Modifications can be made to the special topics course by extending the course to a full semester course, and add practice lab and modules prior to conducting the real-world. Faculty should develop practical classroom labs that will enhance the experience of the servicelearning project. Recommendation to ensure the online students have some of the same experiences as the students that are face-to-face via streaming media. The overall results is that engaging students to participate in project such as the penetration testing project will enable the student to reinforce and apply their knowledge and skill, attain actual experience to be added to resume and gain a respect for team and community collaboration. The soft and technical skills, as well as the needed cybersecurity experience, can bring us step closer to answering the skills gap question. This research added to the body of literature in extending knowledge in team service-learning research, methodology calls for more qualitative research and possible answers to the cybersecurity skills gap. 


\section{References}

Barnett, L., Jeandron, C., \& Patton, M. (2009). Enriched and inspired: Service pathways to college success. Washington. DC: American Association of Community Colleges.

Barr, R. K. (2020). Career development events as a predictor of fall-to-fall retention of first-year college students (Doctoral dissertation, University of Missouri-Columbia).

Barr, J. (2021). The benefits that accrue to students and community partners from embedding servicelearning into the marketing curriculum. Leadership, 2022.

Beasley, S. W., \& Floyd, K. S. (2013). Low-cost, holistic approach to active learning in information technology. Issues in Information Systems, 14(2).

Chan, C. K. Y. (2012). Exploring an experiential learning project through Kolb's Learning Theory using a qualitative research method. European Journal of Engineering Education, 37(4), 405-415.

Chen, Z. (2018). Access and Barriers to Internships for College Students. https://blog.ccwt.wceruw.org/access-and-barriers-to-internships-for-college-students/

Crumpler, W., \& Lewis, J. A. (2019). Cybersecurity Workforce Gap. Center for Strategic and International Studies (CSIS).

Cyber and Information Security Agency (CISA). 2021. Statement from CISA Acting Director Wales on Executive Order to improve the nation's cybersecurity and protect federal networks.. Accessed by https://www.cisa.gov/news/2021/05/13/statement-cisa-acting-director-wales-executive-orderimprove-nations-cybersecurity

Debnath, B. \& Farkhod, A. A. (2009). Penetration Testing for Hire. International Journal of Advanced Science and Technology, Vol (8), p. 1-8.

Duffy, J., Barrington, L., \& Heredia, M. (2009, June). Recruitment, retention, and service learning in engineering. In 2009 Annual Conference \& Exposition (pp. 14-1015).

Elsafty, A., Elsayad, H. I., \& Shaaban, I. (2020). Educating engineering students in Egypt: recommendations for improvement. International Journal of Higher Education, 9(3), 1-14.

Floyd, K. S., Harrington, S. J., \& Santiago, J. (2009). Improving IS student engagement and perceived course value. In Proceedings of the 2009 Southern Association for Information Systems Conference (pp. 24-29).

Furco, A. (1996). Service-learning: A balanced approach to experiential education.

Furnell, S. (2021). The cybersecurity workforce and skills. Computers \& Security. Pg. 1-7.

Girard, J. P., Yerby, J., \& Floyd, K. (2016). Knowledge retention in capstone experiences: An analysis of online and face-to-face courses. Knowledge Management \& E-Learning, 8(4), 528-539. 


\section{Issues in Information Systems}

Volume 22, Issue 3, pp. 307-319, 2021

Graves, K. (2010). CEH certified ethical hacker study guide. John Wiley \& Sons.

Haque, W. (2017, July). Experiential learning: Beyond the classroom and connecting with the industry. In IFIP World Conference on Computers in Education (p. 443-452). Springer, Cham.

Huff, J., Zoltowski, C. B., \& Oakes, W. C. (2016). Preparing engineers for the workplace through service learning: Perceptions of EPICS alumni. Journal of Engineering Education, 105(1), 43-69.

https://doi.org/10.1002/jee.20107.

ISC2. (2020). 2020 Global Information Security Workforce Study: ISC2.

Kolb, A. Y., \& Kolb, D. A. (2005). Learning styles and learning spaces: Enhancing experiential learning in higher education. Academy of management learning \& education, 4(2), 193-212.

Kolb, D. A. (1984). The process of experiential learning. Experiential learning: experience as the source of learning and development. In : (pp. 20-38). Prentice-Hall, Inc..

Kwenani, D. F., \& Yu, X. (2018). Maximizing international students' service-learning and community engagement experience: A case study of student voices on benefits and barriers. Journal of Higher Education Outreach and Engagement, 22(4), p. 29.

Morgan, D. L. (1996). Focus Groups. Annual Review of Sociology, 22, 129-152.

Morgan, D. L. (2002). Focus group interviewing. In J. F. Gubrium, \& J. A. Holstein (Eds.), Handbook of interviewing research: Context \& Method (pp. 141-159). Thousand Oaks, CA: Sage Publications Inc.

Onwuegbuzie, A. J., Dickenson, W. B., Leech, N. L. \& Zoran, A. G. (2009) A qualitative framework for collecting and analyzing data in focus group research, International Institute for Qualitative Methodology, 8(3), pp. 1-21.

Onwuegbuzie, A. J., Dickenson, W. B., Leech, N. L. \& Zoran, A. G. (2009) A qualitative framework for collecting and analyzing data in focus group research, International Institute for Qualitative Methodology, 8(3), pp. 1-21.

Onwuegbuzie, A. J., Dickenson, W. B., Leech, N. L. \& Zoran, A. G. (2009) A qualitative framework for collecting and analyzing data in focus group research, International Institute for QualitativeMethodology, 8(3), pp. 1-21

Onweughbuzie, A.J., Dickenson, W.B., Leech, N.L. \& Zoran, A.G. (2009). A qualitative framework for collecting and analyzing data in focus group research. International Institute for Qualitative Methodology, 8(3), pp. 1-21.

Pazos, P., Cima, F., Kidd, J., Ringleb, S., Ayala, O., Gutierrez, K., \& Kaipa, K. (2020, June). Enhancing Teamwork Skills Through an Engineering Service-learning Collaboration. In 2020 ASEE Virtual Annual Conference Content Access, Virtual Online. 


\section{Issues in Information Systems}

Volume 22, Issue 3, pp. 307-319, 2021

Pinnell, M. F., \& Chuck, L. (2004). Developing technical competency and enhancing the soft skills of undergraduate mechanical engineering students through service-learning. age, 9, 1.

Sayegh, E. (2020). As the end of 2020 approaches, the cybersecurity talent drought gets worse. Forbes. Accessed by https://www.forbes.com/sites/emilsayegh/2020/09/22/as-the-end-of-2020approaches-the-cybersecurity-talent-drought-gets-worse/?sh=5137674e5f86

Wai, T.C., (2002). Conducting a Penetration Test on an Organization, Sans Institute.

Wang, L.F., \& Kou, H.Z. (2012). A research of behavior-based penetration testing model of the network, International Conference on Industrial Control and Electronic Engineering. IEEE. 